\title{
Scientific Practices in Science Education Publications: An Analysis of Research Contexts
}

\author{
Sandro Lucas Reis Costa*, Fabiele Cristiane Dias Broietti \\ Program of Science Teaching and Mathematics Education at State University of Londrina, Londrina, Brazil
}

*Corresponding Author: sandrolucas.costa@uel.br

\section{ABSTRACT}

Scientific Practices play a central role in the Next Generation Science Standards, influencing the standards of more than $70 \%$ of students in the United States. Therefore, a view of what has been studied about Scientific Practices in Science Education, globally in the past decade is relevant. Thus, 44 articles from international journals in Science Education in the past decade (2010-2019) were analyzed. This review focuses on the specific research contexts of these articles. The research objectives were: (1) To identify in which contexts the authors carried out research involving Scientific Practices and (2) to critically discuss the research contexts of Scientific Practices and find research gaps. For this, a systematic literature review was conducted, guided by Bardin's Content Analysis (2011) and the guide to a systematic review by Okoli (2015). Regarding the contexts, six categories were identified: Scientific Practices and teaching proposals (C1); Scientific Practices and distinct theoretical frameworks (C2); Scientific Practices and students (C3); Scientific Practices and assessments (C4); Scientific Practices and teachers (C5); and Scientific Practices and the curriculum (C6). There was a predominant trend to relate Scientific Practices and teaching proposals (38.6\%) and Scientific Practices and different theoretical frameworks (22.7\%), totaling more than $61 \%$ of the analyzed articles. Research gaps have been identified, such as the need for further research on the relationship between Scientific Practices and students (learning) and Scientific Practices and teachers (teaching). Research in this regard can help to clarify: How have students engaged in Scientific Practices? How can teaching be organized to promote Scientific Practices? And what are the relationships between Scientific Practices, school subjects, and specific content? The findings of the study revealed that a greater diversity of research contexts is necessary to fully understand the connections between Scientific Practices and the many dimensions involved in Science Education. It was found that there is a need for more research that addresses Scientific Practices as its main focus, considering the importance the concept is given in guiding documents.

KEY WORDS: international science education; NRC; scientific practices; systematic literature review

\section{INTRODUCTION}

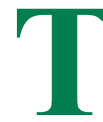
The National Research Council (NRC) published a conceptual framework for Science Education in Basic Education in 2012 titled "A Framework for K-12 Science Education: Practices, Crosscutting Concepts, and Core Ideas." This document represents a recent first step in the strengthening of national science education documents in the United States, developed in the 1990s. The framework is built around three dimensions: (1) Science and Engineering Practices; (2) Crosscutting Concepts; and (3) Disciplinary Core Ideas.

The framework informed the: Next Generation Science Standards (NGSS), considered an interstate movement in the United States that aims to create new science education standards which are rich in content and practice (NGSS, 2013). The objectives of the standards include combating the ignorance of science, creating common standards for teaching in the United States, and increasing interest in science among students.

The standards have the same three dimensions as the NRC document: The Core Ideas, which consist of specific content and thematic fields; Scientific Practices, which guide students to not only learn the content, but also to understand the methods used by scientists and engineers; and Crosscutting Concepts, which are the main underlying ideas common to various topics in science. This research focused only on one of the dimensions, that is, the Scientific Practices.

The relevance of this research is due to the importance given to Scientific Practices in Science Education in recent educational reforms (NRC, 2012; NGSS, 2013), as well as the number of students being taught based on Scientific Practices today. According to the National Science Teaching Association (NSTA) (2019), 44 states (representing 71\% of US students) have standards influenced by the NRC (2012) and 20 states have already adopted the standards, representing more than $35 \%$ of students in the United States. Therefore, the concept of Scientific Practices, one of the three dimensions on which this article focuses, assumes a central role in United States Science Education. In addition, Scientific Practices have been the focus of research in several studies not only in the United States, but also in other countries. In this sense, this research contributes to elucidate the understanding of the concept of Scientific Practice and how this term has been used in international literature. 
The objectives of this research were:

1. To identify in which contexts the authors carried out research involving scientific practices

2. To critically discuss the research contexts of scientific practices and find research gaps.

The research context provided an image of "what" or "who" was related to Scientific Practices in the articles. For example, if the articles related teachers, curriculum, teaching proposals, or other aspects with scientific practices. The contexts identified will be discussed in more detail in the results and discussions section.

The research questions that arose, therefore, were:

1. In which contexts did the authors carry out research involving scientific practices?

2. What discussions can be elaborated about the research contexts of Scientific Practices and what are the research gaps?

The publications analyzed consisted of articles in the field of Science Education published in international journals. The articles were selected through four databases (ERIC, Scielo, Scopus, and Web of Science) published in the 10 years from 2010 to 2019.

\section{THEORETICAL FOUNDATION}

The definition of national goals and standards to meet them are relatively recent strategies in the educational reform policy of the United States (NRC, 1996). The first standards emerged in 1989, with the Curriculum and Evaluation Standards for School Mathematics, prepared by the National Council of Teachers of Mathematics (NCTM, 1989), and with the elaboration of Everybody Counts: A Report to the Nation on the Future of Mathematics Education, by the NRC (1989). A Nation at Risk (National Commission on Excellence in Education, 1983) can also be considered as a relevant precursor document for this movement (NRC, 1996).

In relation to Science, in 1990, the American Association for the Advancement of Science (AAAS), through Project 2061, published Science for All Americans (AAAS, 1990), defining scientific literacy for all high school students. The first standards in Science Education were published in 1996 by the NRC, titled: National Science Education Standards (NRC, 1996) and had a great emphasis on the development of scientific literacy.

The National Science Education Standards of 1996 (NRC, 1996) represent the first set of standards for the Teaching of Sciences and present only four mentions to the term Scientific Practice. The NRC (2012) and NGSS (2013) are different from previous documents, such as the NRC (1996), for example, in that they have a greater emphasis on science learning over the years, centered on the student and oriented through Scientific Practices, Crosscutting Concepts and Core Ideas, with a robust definition and discussion about Scientific Practices and how students can get involved in them. According to the NRC (2012):
Dimension 1 [Scientific Practices] describes (a) the major practices that scientists employ as they investigate and build models and theories about the world and (b) a key set of engineering practices that engineers use as they design and build systems. We use the term "practices" instead of a term such as "skills" to emphasize that engaging in scientific investigation requires not only skill but also knowledge that is specific to each practice. (NRC, 2012. p. 30)

According to the NRC (2012), the focus on Practices (in plural) also helps to avoid the impression that there is a specific, unique or defined approach for all of Science, that is, an infallible method. The Practices described by the NRC derive from those that scientists and engineers actually carry out as part of their work and thus, offer an opportunity for students to immerse themselves in these practices and explore why they are fundamental to Science and Engineering. These are critical movements that promote appreciation for the skills of scientists and engineers. In Table 1 is a brief description of the eight Scientific Practices (SP), organized from SP1-SP8.

\section{METHODOLOGY AND ANALYTICAL PROCEDURES}

Fink (2005) defines a systematic literature review as: A systematic, explicit and reproducible method for identifying, evaluating, and synthesizing the existing body of completed and recorded work produced by researchers, scholars, and practitioners (pp. 3, 17). Okoli (2015) presents a guide (Table 2) for the development of a systematic literature review, in which eight steps are described in detail to ensure a rigorous review that comprehensively summarizes and discusses the existing literature.

In the case of this review, step 1 consisted of elaborating the research problems and justifications, presented in the Introduction. Step 2 consisted of preparing the protocol for the review, that is, the schedule of research activities, as well as the choice of methodological and analytical frameworks. Step 3 consisted of applying the filters, while step 4 consisted of searching the literature. For this review, searches were carried out in four databases: ERIC ${ }^{1}$, Scielo ${ }^{2}$, Scopus ${ }^{3}$, and Web of Science ${ }^{4}$. These databases were selected as they are among the major bibliographic databases used in Science Education research. For all bases, the expression "scientific practice" and "science education" were searched for and the following filters were selected: Articles and review articles 5 ; peer-reviewed journal articles; open access articles; and articles published

\footnotetext{
https://eric.ed.gov

https://scielo.org

https://www.scopus.com/home.uri

4 https://clarivate.com/webofsciencegroup/solutions/web-ofscience

5 Term used in Scopus and Web of Science to search for articles that summarize the current state of understanding of a topic.
} 


\section{Table 1: The scientific practices}

Scientific practice (code)

Asking questions (SP1)

Developing and using models (SP2)

Planning and carrying out investigations (SP3)

Analyzing and interpreting data (SP4)

Using mathematics and computational thinking (SP5)

Constructing explanations (SP6)

Engaging in argument from evidence (SP7)

Obtaining, evaluating, and communicating information (SP8)

\section{Description}

Science starts with a question about a phenomenon and seeks to develop theories that can provide explanatory answers to such questions. A basic practice of the scientist is to ask questions that can be answered empirically, to establish what is already known and to determine which questions can still be answered satisfactorily

Science often involves building and using a wide variety of models and simulations to help develop explanations of natural phenomena. Models make it possible to go beyond what is observable and imagine a world not yet seen

Scientific investigations can be conducted in the field or in the laboratory. An important practice of scientists is to plan and carry out a systematic investigation, which requires the identification of what should be collected, how it should be collected, what should be treated as a dependent variable, etc., The observation and data collected from such works are used to test existing theories and explanations or to review and develop new theories and explanations

Scientific investigations produce data that must be analyzed for meaning. Since the data generally does not speak for itself, scientists use a range of tools, such as: Tabulation, graphical interpretation, visualization, and statistical analysis. These tools are used to identify the significant characteristics and patterns in the data. Technology makes collecting a lot of data much easier, providing many secondary sources for analysis

In science, mathematics and computing are fundamental tools for representing variables and their relationships. These are used for a series of tasks, such as the construction of simulations, statistical analysis of data and recognition of quantitative relationships, for example. Mathematical and computational approaches allow predictions of the behavior of physical systems, along with the confirmation of such predictions. In addition, statistical techniques are invaluable in assessing the significance of patterns or correlations

The goal of science is to build theories that can provide explanatory accounts of features of the world. A theory is accepted when it proves to be superior to other explanations about the phenomena. Scientific explanations are explicit applications of the theory to a specific situation or phenomenon. The students' goal is to build coherent and logical explanations of phenomena that incorporate their current understanding of science, or a representative model consistent with the available evidence

In science, argumentation is essential to identify strengths and weaknesses in a line of reasoning and to find the best explanation for a natural phenomenon. Scientists must know how to defend their explanations, formulate evidence based on a solid database, examine their own understanding in view of the evidence and comments offered by others and collaborate with colleagues in the search for the best explanation for the phenomenon investigated

Scientists must be able to communicate their findings clearly and persuasively, as well as learn about other people's results. One of the main practices of science, therefore, is the communication of ideas and the results of questioning. This includes: Oral information, information in writing, tables, diagrams, graphs, and equations. Science requires the ability to derive meaning from scientific texts (such as journals, internet, conferences, and lectures) to assess scientific knowledge, its validity and integrate this information

Source: Extracted and adapted from NRC (2012), pp. 50-53

\begin{tabular}{ll}
$\begin{array}{l}\text { Table 2: Eight steps for conducting a systematic literature } \\
\text { review }\end{array}$ \\
\hline Step Number & Description \\
\hline 1 & Identify the purpose \\
2 & Draft protocol and train the team \\
3 & Apply practical screen \\
4 & Search for literature \\
5 & Extract data \\
6 & Appraise quality \\
7 & Synthesize studies \\
8 & Write the review \\
\hline
\end{tabular}

Source: Extracted and adapted from Okoli (2015), p. 884 in the 10 years of $2010-2019^{6}$. This time frame was selected as we sought to identify the research contexts of publications, from the past decade, which involved Scientific Practices. This first search generated a total of 58 results.

In step 5, to systematically extract the relevant information for the analysis of the articles, inventories were used. One inventory was filled out for each article to identify the research contexts, as followed in other similar studies (Sousa and Vieira, 2019; Costa et al., 2020a; Costa et al., 2020b; Costa

6 This filter was not available in ERIC, so it had to be filtered manually. 
et al., 2021). To fill in the inventories, the expression "practice" was sought in the body of the article, and all paragraphs that contained this term were read and transcribed to the inventory. We emphasize that we searched for "practice," as this term also showed excerpts of the same word in the plural, "practices," as well as the expression in its complete form "scientific practice." This ensured that all the excerpts that mentioned the term Scientific Practices in the article were transcribed to the inventory. We emphasize that the present review focused only on the research contexts of Scientific Practices. Other research, carried out by the same authors, focused on: Identifying the characteristics of these publications (authors, institutions, continents, countries, publication period, methods, levels of education, areas of knowledge, journals, and main references); and the understandings the authors expressed for the term Scientific Practices.

In step 6, to assess the quality of the inventories, a first reading was carried out. In this process, 14 articles were excluded, according to the following exclusion criteria: Articles that did not belong to the field of Science Education; articles without mention of the term Scientific Practices; duplicate articles between the databases consulted; articles that were not published in journals and articles that were not available in English, Portuguese, or Spanish ${ }^{7}$. Therefore, the corpus of the research was composed of the inventories of 44 articles.

In Table 3, we present the codification of the 44 articles analyzed. The articles were coded according to their sequence of presentation in the databases and not chronologically. The full references of the articles analyzed in the review can be seen in the "References" section at the end of the present article.

For step 7, Okoli (2015) recommends the use of appropriate techniques, whether qualitative or quantitative. In the present review, Bardin's Content Analysis (2011) was used. Bardin (2011) designates content analysis as a set of communication analysis techniques aiming to obtain, by systematic and objective procedures, the description of the content of messages, and indicators (quantitative or not) that allow the inference of knowledge related to the production/reception conditions (inferred variables) of these messages.

Content Analysis is structured in three stages: (1) Pre-analysis; (2) exploration of the material; and (3) treatment of results, inference and interpretation.

In this research, pre-analysis comprised the first contact with the articles, that is, the first reading, as well as the extraction of the necessary information from each article to fill in the inventories, as explained previously.

In this research, the exploration of the material consisted of the coding of articles from A01-A44; and the categorization of articles according to the research contexts (exposed in the results and discussions section). Categorization for Bardin, L. (1977). Content Analysis. Edições (Issues) 70. is an operation

7 Languages the author has proficiency in.

\begin{tabular}{|c|c|}
\hline Code & Article \\
\hline A01 & Houseal (2016) \\
\hline A02 & Valenti et al. (2016) \\
\hline A03 & Rosenberg and Lawson (2019) \\
\hline A04 & Rodriguez et al. (2018) \\
\hline A05 & Nicolaou (2015) \\
\hline A06 & Vick and Garvey (2016) \\
\hline A07 & Buxner (2014) \\
\hline A08 & Lunde et al. (2016) \\
\hline A09 & Buck et al. (2014) \\
\hline A10 & Gunning et al. (2016) \\
\hline A11 & Palma et al. (2017) \\
\hline A12 & Tractenberg (2017) \\
\hline A13 & Riedinger and Taylor (2016) \\
\hline A14 & Ayar and Yalvac (2016) \\
\hline A15 & Brownstein and Horvath (2016) \\
\hline A16 & Bardeen et al. (2018) \\
\hline A17 & Koomen et al. (2014) \\
\hline A18 & Bogar (2019) \\
\hline A19 & Engels et al. (2019) \\
\hline A 20 & Gotwals et al. (2013) \\
\hline A21 & Carpenter (2015) \\
\hline A22 & Erenler and Cetin (2019) \\
\hline A23 & Iwuanyanwu (2019) \\
\hline A24 & Brandão et al. (2011) \\
\hline A 25 & Underwood et al. (2018) \\
\hline A26 & Reed et al. (2017) \\
\hline A27 & Barcellos and Coelho (2019) \\
\hline A28 & Rowland et al. (2018) \\
\hline A29 & Elliott et al. (2016) \\
\hline A 30 & Boisselle (2016) \\
\hline A 31 & Odden and Russ (2019) \\
\hline A 32 & Prins et al. (2018) \\
\hline A33 & Oliva (2019) \\
\hline A34 & López et al. (2018) \\
\hline A35 & Scalise and Clarke-Midura (2018) \\
\hline A36 & Evagorou et al. (2015) \\
\hline A37 & Koomen et al. (2018) \\
\hline A38 & Bierema et al. (2017) \\
\hline A39 & Bargiela et al. (2018) \\
\hline $\mathrm{A} 40$ & Kind and Osborne (2017) \\
\hline A41 & Roberts and Johnson (2015) \\
\hline A42 & Dunlop and Veneu (2019) \\
\hline A 43 & Lombardi et al. (2018) \\
\hline A44 & Wyner and Doherty (2017) \\
\hline
\end{tabular}

Source: The authors

to classify the constituent elements of a set, by differentiation and, subsequently, by grouping according to gender (analogy), with the previously defined criteria.

In this review, the treatment of results, inference and interpretation, consisted of presenting the results of the categorizations and similarities found among the articles involving Scientific Practices in Science Education, as well as the discussion of the results. 
Thus, step 7 by Okoli (2015) involved the three stages of Bardin's Content Analysis (2011). The last step of Okoli (2015), step 8, consisted of writing this review, in which the available material was synthesized and an academic critique of the analyzed studies was conducted.

\section{RESULTS AND DISCUSSION}

Regarding the research contexts of Scientific Practices, six categories were identified that accommodated all the analyzed articles and are presented in Table 4.

Regarding the research contexts identified, category $\mathrm{C} 1$ consisted of articles that investigated/discussed Scientific Practices from different teaching proposals; $\mathrm{C} 2$ consisted of articles that discussed Scientific Practices in a theoretical way; $\mathrm{C} 3$ consisted of articles that investigated the relationship between students and Scientific Practices; C4 consisted of articles that investigated the relationship between scientific practices and assessments; C5 consisted of articles that investigated the relationship between teachers and scientific practices; and C6 consisted of articles that investigated the relationship between Scientific Practices and the curriculum.

We emphasize that the categorizations were carried out in relation to the central focus of the articles, with regard to the discussions involving Scientific Practices, that is, "what" was related to the Scientific Practices. Thus, when the central focus of the article was to report/discuss different teaching proposals, even if the students appeared in these discussions, these articles were allocated to category $\mathrm{C} 1$, for example.

In the following subsections, excerpts from some of the articles are presented and discussed in order to better exemplify the identified categories.

\section{Scientific Practices and Teaching Proposals (C1)}

From Table 4, it was observed that 38.6\% (17 articles) were allocated to category $\mathrm{C} 1$. This category consisted of articles that investigated/discussed Scientific Practices from different teaching proposals developed with students of Basic Education and/or higher education. A03 for example, reported:

These simulation tools - and associated pedagogical approaches - can help learners to develop many of the capabilities recent science education reform efforts aim to promote, particularly students' conceptual understanding, but also their motivation, and their engagement in scientific practices. (A03, p. 3)

It is noted that A03 related simulation tools, a teaching proposal, with the use of computational tools to discuss their potential to promote student engagement in Scientific Practices, as well as other capabilities discussed in educational reforms.

Still in category $\mathrm{C} 1$, an excerpt from A04 is presented below for discussion:

The Boy Scouts of America's Environmental Science and Engineering merit badges are two of their over 120 merit

\begin{tabular}{|c|c|c|}
\hline Category & $\begin{array}{l}\text { Context/brief } \\
\text { description }\end{array}$ & Articles (total) \\
\hline $\mathrm{C} 1$ & $\begin{array}{l}\text { Scientific practices and } \\
\text { teaching proposals }{ }^{8}\end{array}$ & $\begin{array}{l}\mathrm{A} 03, \mathrm{~A} 04, \mathrm{~A} 06, \mathrm{~A} 09, \mathrm{~A} 10, \mathrm{~A} 12, \\
\mathrm{~A} 13, \mathrm{~A} 14, \mathrm{~A} 16, \mathrm{~A} 19, \mathrm{~A} 22, \mathrm{~A} 27, \\
\mathrm{~A} 28, \mathrm{~A} 32, \mathrm{~A} 34, \mathrm{~A} 37, \mathrm{~A} 42(17)\end{array}$ \\
\hline $\mathrm{C} 2$ & $\begin{array}{l}\text { Scientific practices } \\
\text { and distinct theoretical } \\
\text { frameworks }\end{array}$ & $\begin{array}{l}\text { A01, A18, A23, A29, A30, A31, } \\
\text { A33, A36, A40, A41 (10) }\end{array}$ \\
\hline $\mathrm{C} 3$ & $\begin{array}{l}\text { Scientific practices and } \\
\text { students }\end{array}$ & $\begin{array}{l}\text { A02, A05, A11, A21, A38, A43, } \\
\text { A44 (7) }\end{array}$ \\
\hline $\mathrm{C} 4$ & $\begin{array}{l}\text { Scientific practices and } \\
\text { assessments }\end{array}$ & $\mathrm{A} 15, \mathrm{~A} 20, \mathrm{~A} 25, \mathrm{~A} 26, \mathrm{~A} 35$ (5) \\
\hline $\mathrm{C} 5$ & $\begin{array}{l}\text { Scientific practices and } \\
\text { teachers }\end{array}$ & A07, A08, A17, A24 (4) \\
\hline C6 & $\begin{array}{l}\text { Scientific practices and } \\
\text { the curriculum }\end{array}$ & A39 (1) \\
\hline
\end{tabular}

Source: The authors

badges offered as a part of a non-formal educational program to U.S. boys. The Scientific and Engineering Practices of the U.S. Next Generation Science Standards provide a vision of science education that includes integrating eight practices that engage youth in inquiry-based learning and investigative design and interpretation. This exploratory study uses document analysis triangulated with a questionnaire under the general principles of program evaluation as a case study to examine the potential alignment of the Boy Scouts of America's Environmental Science and Engineering merit badges and the Scientific and Engineering Practices of the NGSS. (A04, p. 11675)

A04 seeks to relate Boy Scout badges to the Scientific Practices. In this sense, the article seeks to find evidence on the effectiveness of this proposal as a form of teaching organization that supports the involvement of young people in learning about the Scientific Practices found in the NGSS (2013). In this case, the badges can be considered teaching proposals to promote Scientific Practices.

Among the different teaching proposals related to Scientific Practices, the articles allocated in $\mathrm{C} 1$ discussed the use of simulations (A03); experiments (A04); Boy Scout merit badges (A06); pedagogical approaches for African American girls (A09); parental involvement (A10); a model for statistical literacy (A12); out-of-school time programs (A13); professional development programs (A16); school and university routines (A14); The Confluence Approach program (A19); Argument Driven Inquiry (A22); a class based on inquiry (A27); an online resource (A28); an activity based instructional framework (A32); the interactive digital whiteboard (A34); science fair projects (A37); and controversies in Science (A42).

8 The term teaching proposals was used to maintain a standard. The authors of the articles also used the terms: simulations, experiments, boy scout merit badges, programs, models, online resources, etc. 


\section{Scientific Practices and Distinct Theoretical Frameworks (C2)}

Category C2 accommodated $22.7 \%$ (10 articles). The articles allocated in this category discuss Scientific Practices in a theoretical way, relating them to different theoretical frameworks. An excerpt from A01 is presented below for discussion:

Beginning with the known, by using specific examples from the NGSS and traditional school-science culture, the article provides examples of the dimensions singularly, in tandem, and finally all together. Understanding how the three dimensions interact is a critical first step for schools, districts, and states considering the Framework and NGSS for full or partial adoption, as it helps to illuminate where we are coming from and where we need to go. (A01, p. 1)

A01 discusses the Scientific Practices in a theoretically, relating them to the NGSS (2013), that is, articulating them with the other dimensions - Crosscutting Concepts and Disciplinary Core Ideas. The article also presents different examples of Scientific Practices in isolation and in combination in order to understand their interactions and describe how the practices can manifest themselves in the classroom.

Still in category $\mathrm{C} 2$, an excerpt from A18 is presented next:

When it comes to scientific practices, educational reforms highly emphasize scientific practices such as argumentation in science education. Therefore, the purpose of this study is to conduct a synthesis study on argumentation in science education. (A18, p. 1)

In this sense, A18 discusses, in more detail, the Scientific Practice of argumentation in a theoretical manner, summarizing seven main headings of argumentation found in Science Education literature. The article also highlights the emphasis given to Scientific Practices in educational reforms in Science Education.

Among the different theoretical approaches of the articles allocated in $\mathrm{C} 2$, they discuss: the articulation and exemplification of Scientific Practices in the classroom (A01); a study of the Scientific Practice of argumentation in Science Education (A18); what is taught in Science and what students learn, highlighting the importance of Scientific Practices to build an understanding of the Nature of Science (A23); how interactive accounts of scientific methods developed by historians and philosophers of science give sense to specific Scientific Practices (A29); how the remaining or transformed colonialist structures continue to shape science and science education (A30); the theoretical fragmentation of the concept of sense making in literature (A31); five meanings for modeling, as one being a Scientific Practice (A33); visual representations as epistemic objects of Scientific Practices (A36); scientific reasoning in 6 styles, as a Scientific Practice (A40); that a conceptual knowledge base for understanding data quality represents an ontological change that addresses some long-standing issues in Science Education research, policy, curriculum, and practice (A41).

\section{Scientific Practices and Students (C3)}

Category $\mathrm{C} 3$ corresponded to $15.9 \%$ (7 articles). The articles allocated to this category discuss aspects of Scientific Practices focusing on the students. These articles investigated the beliefs, emotions, ideas, understandings and knowledge of students from different levels of education, as well as some relationships with scientific practices.

Below is an excerpt from A02 for discussion:

The current study examines implicit attitudes against science among adolescents (ages 14-17) and college students, and examines an aspect as yet unstudied, but recognized as important by educators: The belief that science is not creative. Regrettably, we predict that students as young as 14 might already have come to the implicit conclusion that science consists of established findings about the world, rather than a creative process of investigation. (A02, p. 44)

It is noted that A02 investigates students' implicit beliefs and attitudes. In this sense, the investigated students presented notions that the daily practice of science is non-creative and socially isolated. A02's results also show the importance of developing Scientific Practices for students' interest in science and scientific careers.

The articles allocated in $\mathrm{C} 3$ investigated the relationship between Scientific Practices and students, more specifically: Their beliefs and attitudes against science (A02); their emotions about the learning environment (A05); their ideas about how astronomers study the solar system (A11); their ideas about science teaching and learning (A21); their attitudes during the development of scientific models (A38); their plausibility judgments and knowledge during an activity based on critical thinking (A43); and their understandings of the patterns of evolution (A44).

\section{Scientific Practices and Assessments (C4)}

Category C4 corresponded to $11.4 \%$ (5 articles). In this category, articles that discuss aspects of Scientific Practices focusing on different types of assessments were allocated. These articles investigated: Didactic performance assessment portfolios, ecology items in large scale assessments, school assessment items, chemistry items in large scale assessments, and a virtual performance assessment task.

We present an excerpt from A15 for discussion:

Science education and teacher performance assessment experts have developed a crosswalk designed to highlight specific tasks within the secondary science edTPA ("educative" Teacher Performance Assessment); in these tasks, pre-service science teachers are prompted to plan, teach and assess their students as they engage in learning science explicitly aligned with the NGSS. The researchers in this study used qualitative methods to analyze archived actual pre-service science teacher edTPA portfolio artifacts to test the efficacy of this crosswalk. Evidence of student engagement in the NGSS scientific practices was found, confirming some components, and modifications of the NGSS and edTPA Crosswalk are suggested based on the results. (A15, p. 44) 
It is noted that $\mathrm{A} 15$ analyzed portfolios of science teachers in pre-service education. The edTPA is an assessment and support system based on teacher performance, specific to each subject and used by teacher education programs across the United States. The edTPA is a specific assessment for each discipline focused on three tasks: Planning, Instruction, and Evaluation. Thus, A15 sought to assess the intersection between edTPA and recommendations suggested by the NGSS, including the development of Scientific Practices.

A20, on the other hand, sought to investigate what core ecological ideas and Scientific Practices certain large-scale assessments items require from urban students. The article also investigates which aspects of these assessments are difficult for a specific group of urban high school students.

Among the articles allocated to category $\mathrm{C} 4$, these investigated: Portfolios used to evaluate the didactic performance of preservice teachers in science (A15); ecology items of largescale assessments (A20); ways to adapt assessments to better fit teaching based on Scientific Practices, Core Ideas and Crosscutting Concepts (A25); how Scientific Practices have been incorporated into assessments to assess students' knowledge of Chemistry (A26); and whether evidence can be obtained from a Virtual Performance Assessment (VPA) task to produce an estimate of students' Scientific Practices of inquiry (A35).

\section{Scientific Practices and Teachers (C5)}

Category C 5 corresponded to $9.1 \%$ (4 articles). In this category, articles that discuss aspects of Scientific Practices focusing on teachers were allocated. These articles investigated changes in teachers' conceptions, negotiations of the meaning of teachers' lab work, classroom instruction after participating in a professional development program, and a questionnaire to assess teachers' conceptions about modeling and science.

Next is an excerpt from A07 for discussion:

This qualitative interpretive study used an adapted Views of Nature of Science and Views on Scientific Inquiry surveys and protocols to investigate changes in 43 practicing teachers' understandings about the nature of science and scientific inquiry as a result of participation in one of three summer science research programs. Each program provided participants with research experiences alongside professional researchers as well as activities intended to increase participants' abilities to provide inquiry-based science learning activities for their students. (A07, p. 53)

It is noted that A07 investigated changes in teachers' conceptions during participation in a research program. According to A07, the participation of teachers, during their teacher education, in research experiences can contribute to teaching based on the use of Scientific Practices. Despite this, more research is needed to examine the changing conceptions and attitudes of teachers exposed to these experiences.

A08, on the other hand, investigated the negotiation of teachers' meaning about laboratory work in a professional development program. It was observed difficulty for teachers to distinguish between science as a product and a process and, therefore, the ability to combine laboratory work as a teaching method that mirrors Scientific Practices and provides an insight into the nature of science.

In relation to Scientific Practices, the articles allocated to C5 discussed that scientific research experiences for teachers can help them to involve their students in Scientific Practices (A07); some teachers understood laboratory work as a way of mirroring Scientific Practices (A08); the summer professional development program: Summer Ecology Institute for Teachers, which aimed to promote situations in which teachers and their students were able to learn science in ways that reflect scientific methods and Scientific Practices (A17); the validation of a questionnaire that investigates teachers' conceptions about science and modeling, since scientific modeling can favor an adequate view of science for Scientific Practices (A24).

\section{Scientific Practices and the Curriculum (C6)}

Category C6 corresponded to $2.3 \%$ ( 1 article). This category investigates aspects of Scientific Practices focusing on the curriculum. Next is an excerpt from A39 for discussion:

This paper presents a study about scientific practices in the curriculum and in teacher training plans in science in Early Childhood Education (ECE). The research questions are:

1. How are scientific practices integrated in the ECE curriculum? (A39, p. 7)

Thus, we note that A39 investigated the curriculum of ECE, as well as the initial training of teachers, to find out how Scientific Practices are inserted in the curriculum of this level of education.

\section{A Critical Analysis of the Research Contexts}

Table 5 shows the research contexts regarding Scientific Practices, investigated by the authors of the analyzed articles.

The most representative context of the corpus was: Scientific Practices and teaching proposals (C1). Regarding the representativeness of each research context, we present Figure 1, in which the six research contexts are represented by six circular nodes ${ }^{9}$. Each node contains a title indicating the research context and the percentage of articles allocated. The diameters of the nodes are equivalent to the percentages, facilitating the visualization of the more and less representative research contexts.

From Table 5 and Figure 1, we observe a greater trend to study Scientific Practices and teaching proposals, that is, articles that discuss aspects of Scientific Practices from different teaching proposals $(\mathrm{C} 1)$.

Discussions regarding Category $\mathrm{C} 1$ in this article allow knowledge of the specific approaches which have been

9 Term used to designate graphic objects used to visually represent geometric information, an entity or any other types of data. 


\begin{tabular}{llc}
\hline \multicolumn{3}{l}{ Table 5: $R$ Research contexts investigated } \\
\hline Category & Context & Number of articles (\%) \\
\hline C1 & $\begin{array}{l}\text { Scientific practices and teaching } \\
\text { proposals }\end{array}$ & $17(38.6)$ \\
C2 & $\begin{array}{l}\text { Scientific practices and distinct } \\
\text { theoretical frameworks }\end{array}$ & $10(22.7)$ \\
C3 & $\begin{array}{l}\text { Scientific practices and students } \\
\text { C4 }\end{array}$ & $7(15.9)$ \\
C5 & $\begin{array}{l}\text { assentific practices and } \\
\text { Scientific practices and teachers }\end{array}$ & $5(11.4)$ \\
C6 & $\begin{array}{l}\text { Scientific practices and the } \\
\text { curriculum }\end{array}$ & $4(9.1)$ \\
\hline
\end{tabular}

Source: The authors



Figure 1: Diagram of the representativeness of the research contexts Source: The authors

related to Scientific Practices so far. The identification of such approaches allows other researchers to know the approaches investigated so far and their potential for involvement in Scientific Practices, as well as to investigate the potential of other approaches not yet explored.

On the other hand, an emphasis solely on teaching proposals and the potentials these have, for example, in engaging students with Scientific Practices, promoting critical thinking, presenting Crosscutting Concepts, or Disciplinary Core Ideas without a focus also on the students involved could overlook analyses on the learning processes students go through (Costa et al., 2021). In fact, there was little research that investigated students and Scientific Practices (7 articles) and even less that investigated teachers and Scientific Practices (4 articles). More research is needed to investigate the relationship between Scientific Practices and students and Scientific Practices and teachers, that is, the subjects involved in the teaching and learning processes of Science Education. Research in this direction will allow us to understand: how teachers have been incorporating Scientific Practices in their lesson plans and lessons; and which Scientific Practices are being developed more and less intensively by teachers. In addition, research in this sense could allow a clearer view of how students have been engaging with Scientific Practices, as well as, whether engagement in Scientific Practices has provided a better understanding of the content and nature of science.

Another research context that presented few articles was: Scientific Practices and assessments (C4). Category C4 contained only five articles (11.4\%). Studies that investigate the relationship between assessments, especially large scale assessments, and Scientific Practices are relevant due to the large scale impact the Next Generation Science Standards (NGSS, 2013) and the NRC framework (NRC, 2012) have had in students' Science Education throughout the United States as a whole (Broietti et al., 2019).

Learning progressions ${ }^{10}$ need to be elaborated for different contents of Science and their specific subjects (Chemistry, Physics, Biology, etc.), to give suggestions of how to work each Practice in different school years, in a progressive manner. In the analyzed corpus, a similar study was carried out only by article A44 for evolution. Other learning progressions also need to be elaborated for other core content. This can contribute to a better understanding of how Scientific Practices can be articulated over the school years, and will also help to better understand which subjects and contents have the greatest potential to involve students in specific Scientific Practices. Research in this regard is recommended by the NRC (2012), as it helps to support teachers in adopting Science Teaching involving Scientific Practices.

Further research is also needed involving Scientific Practices in initial teacher training. Few articles investigated preservice teachers $(2.3 \%)$. A21, for example, investigated undergraduates' ideas about science teaching and learning after participating in outreach programs. More research involving undergraduates is relevant, as including discussions about the articulation of Scientific Practices in initial training will make future teachers more confident in involving these practices in teaching experiences. This type of research can present results about these processes. This is in line with the low number of articles involving Scientific Practices and the curriculum (2.3\%). Only A39 studied Scientific Practices in the curriculum and science training plans in ECE. A39 also reported that there was mention of Scientific Practices in two subjects in the initial training of Science teachers; however, more research in other contexts needs to be carried out.

\section{FINAL CONSIDERATIONS}

Given the results of this study, we return to our research questions: (1) In which contexts did the authors carry out research involving Scientific Practices? (2) What discussions can be elaborated about the research contexts of Scientific Practices and what are the research gaps?

10 Suggestions on how to work each Scientific Practice in different school years, progressively. 
Among the 44 articles analyzed involving Scientific Practices in Science Education, only $38.6 \%$ presented the term Scientific Practices in the research objectives and problems. This is due to the fact that many articles did not have a main focus on this topic. A great trend found was to relate Scientific Practices to teaching proposals $(\mathrm{C} 1)$. These articles often sought to identify the potential of certain teaching proposals and found that the promotion of Practices was one of them. Thus, discussions about Scientific Practices were complementary in many articles. Despite this, all articles in the corpus presented the term in the abstract. Therefore, we consider that there is a gap in the existing research. There is a need for more research with the main focus on Scientific Practices and teaching/ learning in Science in three dimensions (Scientific Practices, Crosscutting Concepts and Core Ideas). The list of articles that investigated Scientific Practices with greater emphasis was: A01, A06, A09, A12, A17, A20, A25, A26, A28, A29, A33, A34, A37, A38, A39, A41, and A44. These articles can serve as a reading base for researchers who wish to develop future research on the topic.

The biggest trends among the research contexts were: Scientific Practices and teaching proposals (38.6\%) and Scientific Practices and distinct theoretical frameworks (22.7\%), totaling $61.3 \%$ of the analyzed articles. Few articles investigated the relationship between Scientific Practices and students (15.9\%) and Scientific Practices and teachers (9.1\%). Therefore, more research is needed to investigate the relationship between Scientific Practices and students and Scientific Practices and teachers. Research in this sense has implications for a greater understanding of how teachers are integrating Science Teaching and the Practices and how students are engaging with Scientific Practices in different subjects and contents.

\section{REFERENCES}

American Association for the Advancement of Science. (1990). Science for all Americans. American Association for the Advancement of Science.

Ayar, M.C., \& Yalvac, B. (2016). Lessons learned: Authenticity, interdisciplinarity, and mentoring for STEM learning environments. International Journal of Education in Mathematics, Science and Technology, 4(1), 30-43.

Barcellos, L.S., \& Coelho, G.R. (2019). An analysis of discursive interactions in an investigative science class in the early years of elementary school about protective measures against sun exposure. Investigations in Science Teaching, 24(1), 179-199.

Bardeen, M., Wayne, M., \& Young, M.J. (2018). Quarknet: A unique and transformative physics education program. Education Sciences, 8(1), $1-10$.

Bardin, L. (2011). Content Analysis. Edições (Issues) 70.

Bargiela, I.M., Mauriz, B.P., \& Anaya, P.B. (2018). Scientific practices in children: An approach to the analysis of the curriculum and training plans for teachers in Galicia. Science Education: Magazine of Investigation and Didactic Experiences, 36(1), 7-23.

Bierema, A.M.K., Schwarz, C.V., \& Stoltzfus, J.R. (2017). Engaging undergraduate biology students in scientific modeling: Analysis of group interactions, sense-making, and justification. CBE Life Sciences Education, 16(4), 68.

Bogar, Y. (2019). Synthesis study on argumentation in science education. International Education Studies, 12(9), 1-14.

Boisselle, L.N. (2016) Decolonizing science and science education in a postcolonial space (Trinidad, a developing Caribbean nation, illustrates).
Sage Open, 6(1), 1-11.

Brandão, R.V., Araujo, I.S., Veit, E.A., \& da Silveira, F.L. (2011). Validation of a questionnaire to investigate teachers' conceptions about science and scientific modeling in the context of physics. Revista Electrónica de Investigación en Educación en Ciencias, 6(1), 43-61.

Broietti, F.C.D., Nora, P.S., \& Costa, S.L.R. (2019). Dimensions of science learning: A study on PISA test questions involving chemistry content. Acta Scientiae, 21(1), 95-115.

Brownstein, E.M., \& Horvath, L. (2016). Next generation science standards and edTPA: Evidence of science and engineering practices. Electronic Journal of Science Education, 20(4), 44-62.

Buck, G.A., Akerson, V.L., Quigley, C.F., \& Weiland, I.S. (2014). Exploring the potential of using explicit reflective instruction through contextualized and decontextualized approaches to teach first-grade African American girls the practices of science. Electronic Journal of Science Education, 18(6), 1-21.

Buxner, S.R. (2014). Exploring how research experiences for teachers changes their understandings of the nature of science and scientific inquiry. Journal of Astronomy and Earth Sciences Education, 1(1), 53-68.

Carpenter, S.L. (2015). Undergraduates' perceived gains and ideas about teaching and learning science from participating in science education outreach programs. Journal of Higher Education Outreach and Engagement, 19(3), 113-146.

Costa, S.L.R., Bortoloci, N.B., Broietti, F.C.D., Vieira, R.M., \& TenreiroVieira, C. (2021). Pensamento crítico no ensino de ciências e educação matemática: Uma revisão bibliográfica sistemática. Investigations in Science Teaching, 26(1), 145-168.

Costa, S.L.R., Obara, C.E., \& Broietti, F.C.D. (2020a). Critical thinking in science education and mathematics education: Research trends of 20102019. Research Society and Development, 9(9), 1-30.

Costa, S.L.R., Obara, C.E., \& Broietti, F.C.D. (2020b). Critical thinking in science education publications: The research contexts. International Journal of Development Research, 10, 39438-39448.

Dunlop, L., \& Veneu, F. (2019). Controversies in science. Science and Education, 28(6), 689-710.

Elliott, K.C., Cheruvelil, K.S., Montgomery, G.M., \& Soranno, P.A. (2016), Conceptions of good science in our data-rich world. BioScience, 66(10), 880-889.

Engels, M., Miller, B., Squires, A., Jennewein, J.S., \& Eitel, K. (2019). The confluence approach: Developing scientific literacy through projectbased learning and place-based education in the context of NGSS. Electronic Journal of Science Education, 23(3), 33-58.

Erenler, S., \& Cetin, P.S. (2019). Utilizing argument-driven-inquiry to develop pre-service teachers' metacognitive awareness and writing skills. International Journal of Research in Education and Science, $5(2), 628-638$.

Evagorou, M., Erduran, S., \& Mäntylä, T. (2015). The role of visual representations in scientific practices: From conceptual understanding and knowledge generation to "seeing" how science works. International Journal of STEM Education, 2(1), 1-13.

Fink, A. (2005). Conducting Research Literature Reviews: From the Internet to Paper $2^{\text {nd }}$ ed. Sage.

Gotwals, A.W., Hokayem, H., Song, T., \& Songer, N.B. (2013). The role of disciplinary core ideas and practices in the complexity of large-scale assessment items. Electronic Journal of Science Education, 17(1), 1-25.

Gunning, A.M., Marrero, M.E., \& Morell, Z. (2016). Family learning opportunities in engineering and science. Electronic Journal of Science Education, 20(7), 1-25.

Houseal, A.K. (2016). A visual representation of three dimensional learning: A model for understanding the power of the framework and the NGSS. Electronic Journal of Science Education, 20(9), 1-7.

Iwuanyanwu, P.N. (2019). What we teach in science, and what learners learn: A gap that needs bridging. Online Submission, 4(2), 1-12.

Kind, P., \& Osborne, J. (2017). Styles of scientific reasoning: A cultural rationale for science education? Science Education, 101(1), 8-31.

Koomen, M.H., Blair, R., Young-Isebrand, E., \& Oberhauser, K.S. (2014). Science professional development with teachers: Nurturing the scientist within. Electronic Journal of Science Education, 18(6), 1-28.

Koomen, M.H., Rodriguez, E., Hoffman, A., Petersen, C., \& Oberhauser, 
K. (2018). Authentic science with citizen science and student-driven science fair projects. Science Education, 102(3), 593-644.

Lombardi, D., Bickel, E.S., Bailey, J.M., \& Burrell, S. (2018). High school students' evaluations, plausibility (re) appraisals, and knowledge about topics in Earth science. Science Education, 102(1), 153-177.

López, V., Grimalt-Álvaro, C., \& Couso, D. (2018). How does the Interactive Whiteboard (IWB) help to promote inquiry and modeling practices in the science classroom? Eureka Magazine on Teaching and Dissemination of the Sciences, 15(3), 330201-330215.

Lunde, T., Rundgren, S.N.C., \& Drechsler, M. (2016). Exploring the negotiation of the meaning of laboratory work in a continuous professional development program for lower secondary teachers. Electronic Journal of Science Education, 20(8), 26-48.

National Commission on Excellence in Education. (1983). A nation at risk: The imperative for educational reform. The Elementary School Journal, 84(2), 113-130.

National Council of Teachers of Mathematics. (1989). Curriculum and Evaluation Standards for School Mathematics. National Council of Teachers of Mathematics.

National Research Council (NRC). (1989). Everybody Counts: A Report to the Nation on the Future of Mathematics Education. Washington, DC, United States: National Academies Press.

National Research Council. (1996). National Science Education Standards. National Academy Press.

National Research Council. (2012). A Framework for K-12 Science Education: Practices, Crosscutting Concepts, and Core Ideas. National Academies Press.

National Science Teaching Association. (2019). K-12 Science Standards Adoption. Available from: https://www.ngss.nsta.org/About.aspx.

NGSS Lead States. (2013). Next Generation Science Standards: For States, By States. National Academies Press.

Nicolaou, C. (2015). Elementary school students' emotions when exploring an authentic socio-scientific issue through the use of models. Science Education International, 26(2), 240-259.

Odden, T.O.B., \& Russ, R.S. (2019). Defining sensemaking: Bringing clarity to a fragmented theoretical construct. Science Education, 103(1), 187-205.

Okoli, C. (2015). A guide to conducting a standalone systematic literature review. Communications of the Association for Information Systems, 37(43), 879-910.

Oliva, J.M. (2019). Different meanings for the idea of modeling in science teaching. Enseñanza de las Ciencias, 37(2), 5-24.

Palma, C., Plummer, J., Rubin, K., Flarend, A., Ong, Y.S., McDonald, S., Ghent, C., Gleason, T., \& Furman, T. (2017). Have astronauts visited neptune? Student ideas about how scientists study the solar system. Journal of Astronomy and Earth Sciences Education, 4(1), 63-74.

Prins, G.T., Bulte, A.M., \& Pilot, A. (2018). Designing context-based teaching materials by transforming authentic scientific modelling practices in chemistry. International Journal of Science Education, 40(10), 1108-1135.

Reed, J.J., Brandriet, A.R., \& Holme, T.A. (2017). Analyzing the role of science practices in ACS exam items. Journal of Chemical Education, 94(1), 3-10.

Riedinger, K., \& Taylor, A. (2016). I could see myself as a scientist: The potential of out-of-school time programs to influence girls' identities in science. Afterschool Matters, 23, 1-7.

Roberts, R., \& Johnson, P. (2015). Understanding the quality of data: A concept map for "the thinking behind the doing" in scientific practice. The Curriculum Journal, 26(3), 345-369.

Rodriguez, B., Jaramillo, V., Wolf, V., Bautista, E., Portillo, J., Brouke, A., Min, A., Melendez, A., Amann, J., Pena-Francesch, A., \& Ashcroft, J. (2018). Contextualizing technology in the classroom via remote access: Using space exploration themes and scanning electron microscopy as tools to promote engagement in geology/chemistry experiments. Journal of Technology and Science Education, 8(1), 86-95.

Rosenberg, J.M., \& Lawson, M.A. (2019). An investigation of students' use of a computational science simulation in an online high school physics class. Education Sciences, 9(1), 1-19.

Rowland, S., Hardy, J., Colthorpe, K., Pedwell, R., \& Kuchel, L. (2018). CLIPS (communication learning in practice for scientists): A new online resource leverages assessment to help students and academics improve science communication. Journal of Microbiology and Biology Education, 19(1), 1-4.

Scalise, K., \& Clarke-Midura, J. (2018). The many faces of scientific inquiry: Effectively measuring what students do and not only what they say. Journal of Research in Science Teaching, 55(10), 1469-1496.

Sousa, A.S., \& Vieira, R.M. (2019). Critical thinking in Science education: Review of studies in Basic Education in Portugal. Faculty Magazine of Education, 29(1), 15-33.

Tractenberg, R.E. (2017). How the mastery rubric for statistical literacy can generate actionable evidence about statistical and quantitative learning outcomes. Education Sciences, 7(1), 1-16.

Underwood, S.M., Posey, L.A., Herrington, D.G., Carmel, J.H., \& Cooper, M.M. (2018). Adapting assessment tasks to support three-dimensional learning. Journal of Chemical Education, 95(2), 207-217.

Valenti, S.S., Masnick, A.M., Cox, B.D., \& Osman, C.J. (2016). Adolescents' and emerging adults' implicit attitudes about STEM careers: Science is not creative. Science Education International, 27(1), 40-58.

Vick, M.E., \& Garvey, M.P. (2016). Environmental science and engineering merit badges: An exploratory case study of a non-formal science education program and the US scientific and engineering practices. International Journal of Environmental and Science Education, 11(18), 11675-11698.

Wyner, Y., \& Doherty, J.H. (2017). Developing a learning progression for three-dimensional learning of the patterns of evolution. Science Education, 101(5), 787-817. 